\title{
A EFETIVIDADE DOS DIREITOS FUNDAMENTAIS SOCIAIS E A PROTEÇÃO DO CONTEÚDO MÍNIMO PARA GARANTIA DA DIGNIDADE DA PESSOA HUMANA
}

\section{THE EFFECTIVENESS OF FUNDAMENTAL SOCIAL RIGHTS AND THE PROTECTION OF MINIMUM CONTENT TO GUARANTEE THE DIGNITY OF THE HUMAN PERSON}

\author{
Helena Liebl ${ }^{1}$ \\ Luciana Carvalho de Paulo Coelho
}

Resumo: A presente pesquisa características e a diferença com teve como objetivo tratar da efe- Direitos Patrimoniais, enfocando, tividade dos Direitos Fundamen- brevemente, os princípios constitais Sociais, protegendo o conteú- tucionais da proporcionalidade e do mínimo existencial a fim de razoabilidade na aplicação dos garantir o Princípio da Dignidade direitos fundamentais e a fiscalida Pessoa Humana. Para tanto, zação de normas perante a vioabordou-se sobre o conceito ge- lação deste. Após, partiu-se para ral dos direitos fundamentais, uma aplicabilidade específica, identificando as suas principais explicando o que são os direitos

1 Advogada. Mestranda em Ciência Jurídica pela UNIVALI, com dupla titulação, na Universidade de Alicante/Espanha. Membro imortal da Academia de Letras do Brasil de Santa Catarina Seccional de Balneário Piçarras. E-mail: helenali.liebl@gmail.com

2 Professora da UNIVALI - Itajaí. Doutora em Ciência Jurídica pela UNIVALI. Advogada. E-mail: lupaulocoelho@yahoo.com.br 
fundamentais sociais para, então, tratar sobre o conteúdo mínimo existencial e a justiciabilidade de tais direitos, relacionando-se com a Teoria da Reserva do Possível e o seu uso perante o Poder Judiciário como alegação do Estado para afastar o conteúdo mínimo existencial do dever deste em aplicar os direitos fundamentais sociais. Tratou-se também sobre a eficácia social de tais direitos, já que demandam a distribuição de recursos do Estado e a prática de políticas públicas para torná-los efetivos socialmente. O Princípio da Dignidade da Pessoa Humana foi tratado para explicar a sua relação com os direitos fundamentais sociais. Por isso, faz-se necessária uma análise da efetividade dos direitos fundamentais sociais, pois, não sendo efetiva a aplicabilidade deles, não há o que se falar em Dignidade da Pessoa Humana, já que aqueles são precursores desta. Quanto à metodologia, foram utilizadas as técnicas do referente, da pesquisa bibliográfica, da categoria e do conceito operacional.

Palavras-chave: Direitos Fundamentais. Efetividade. Conteúdo Mínimo. Dignidade da Pessoa Humana.

Abstract: This research aimed to address the effectiveness of Fundamental Social Rights, protecting the minimum existential content in order to guarantee the Principle of Human Dignity. To this end, we approached the general concept of fundamental rights, identifying its main characteristics and the difference with Patrimonial Rights, starting briefly to focus on the constitutional principles of proportionality and reasonableness in the application of fundamental rights and the inspection of norms before its violation. Afterwards, it started with a specific applicability, explaining what the fundamental social rights are, then dealing with the minimum existential content and the justiciability of such rights, relating to the Theory of the Possible Reserve and its use before the Judiciary as the State's claim to remove the minimum existential content from its duty to apply fundamental social rights. It also dealt with the social effectiveness of such rights, as they demand the distribution of State resources and the practice of public policies to make them socially effective. The principle of the Dignity of the Human Person has been addressed to explain its relation to fundamental social rights. For this reason, an analysis of the effectiveness of fundamental social rights is necessary, as their applicability is not effective, there is nothing to be said about the Dignity of the Human Person, since those are precursors of that. 
As for the methodology, the tech- Keywords: Fundamental Rights. niques of referent, bibliographic Effectiveness. Minimum Conresearch, category and operational tent. Dignity of Human Person. concept had been used.

\section{INTRODUÇÃO}

Tendo em vista a sistemática da Constituição de 1988, tem-se que direitos fundamentais é gênero que abrange as seguintes espécies: direitos individuais, coletivos, sociais, nacionais e políticos.

Como o próprio título do presente estudo trata de Direitos Fundamentais Sociais, focar-se-á nesses direitos subjetivos, que têm como condição de existência ou vigor no ordenamento jurídico a previsão na Constituição.

Assim, a pesquisa tem como objetivo a análise da necessidade da garantia da efetividade do conteúdo mínimo dos Direitos Sociais para garantia do Princípio da Dignidade da Pessoa Humana.

Tratar-se-á, portanto, da efetividade dos Direitos Fundamentais Sociais e seu conteúdo mínimo para garantir o princípio citado anteriormente, também assegurado pela Carta Magna.

Traçou-se como objetivo primordial da pesquisa investigar os Direitos Fundamentais e a relevância da efetividade de um conteúdo mínimo dos Direitos Sociais.

Assim, no primeiro tópico, será tratado o conceito geral de Direitos Fundamentais, partindo-se para uma aplicabilidade específica sobre os Direitos Fundamentais Sociais. No terceiro tópico, será analisada a Eficácia Social de tais Direitos. Após, será feita a análise do conteúdo mínimo desses Direitos, para, enfim, no quinto tópico, analisar o Princípio da Dignidade da Pessoa Humana. 
Quanto à metodologia empregada neste trabalho, foram utilizadas as técnicas do referente, do conceito operacional, da categoria e da pesquisa bibliográfica.

\section{DIREITOS FUNDAMENTAIS}

A Carta Magna de 1988 foi a primeira a fixar os Direitos Fundamentais antes da organização do Estado, o que realça a relevância desses na nova ordem democrática que fora estabelecida no País após longos anos de Ditadura (BRASIL, 2006).

Para Firmino (2013, p. 127), Direitos Fundamentais "são aqueles direitos inerentes à própria condição humana e que estão previstos pelo ordenamento jurídico". Ainda explica que são tidos como fundamentais porque dizem respeito a situações jurídicas sem as quais as pessoas não sobreviveriam (FIRMINO, 2013, p.128).

Rodrigo Pinho (2008, p. 69) conceitua tais direitos da seguinte maneira:

Direitos Fundamentais são os considerados indispensáveis à pessoa humana, necessários para assegurar a todos uma existência digna, livre e igual. Não basta ao Estado reconhecê-los formalmente; deve buscar concretizá-los, incorporá-los no dia-a-dia dos cidadãos e de seus agentes.

Direitos Fundamentais são os direitos atribuídos universalmente a todos os cidadãos capazes de agir. Essa definição apenas expressa o que são Direitos Fundamentais, mas não quais são esses direitos. Luigi Ferrajoli (2011, p. 9) assim define Direitos Fundamentais:

São todos aqueles direitos subjetivos que dizem respeito universalmente a todos os seres humanos enquanto dotados do status de pessoa, ou de cidadão ou de pessoa capaz de agir. Compreendo por "direito subjetivo" qualquer expectativa positiva (a prestação) ou negativa (a não 
lesão) vinculada a um sujeito por uma norma jurídica, e por status a condição de um sujeito prevista também está por uma norma jurídica positiva qual pressuposto da sua idoneidade a ser titular de situações jurídicas e/ou autor dos atos que estão em exercício.

Para o mesmo autor, esses direitos são conquistados a preços de lutas e revoluções. Eles são absolutos em relação aos seus titulares normativamente reconhecidos, ou seja, têm as condições de titularidade, quais sejam: personalidade, cidadania e capacidade de agir. Esses direitos foram gradualmente sendo estendidos a outros grupos da sociedade, pois, no passado, eram extremamente restritos ao sexo, ao nascimento, à instrução ou à nacionalidade (FERRAJOLI, 2011, p. 9).

$\mathrm{O}$ fato de os Direitos Fundamentais serem para todos os cidadãos remete para a evidência de que, por via de regra, seja conferido de modo igualitário a todos os cidadãos, o que, infelizmente, não se observa na sociedade, pois a efetividade desses direitos é influenciada por várias questões e nem todos têm acesso às garantias e aos direitos constitucionalmente positivados e destinados a todos.

Nesse contexto, Ferrajoli (2011, p. 93) afirma:

Se queremos garantir um direito como "fundamental" devemos subtraí-lo da disponibilidade política e da disponibilidade do mercado, formulando-o na forma de uma regra geral e por isso conferindo-lhe igualmente a todos.

Com base no que afirmou Ferrajoli (2011, p. 9), extrai-se a Teoria da Reserva do Possível quando o autor cita a "disponibilidade política e disponibilidade do mercado".

Essa definição de Direitos Fundamentais, proposta por vários doutrinadores, se fundamenta em quatro teses.

Diferencia estruturalmente os direitos fundamentais e os direitos patrimoniais, onde os primeiros se relacionam a 
classe de sujeitos, e os segundos a qualquer dos titulares, com exclusão de todos os outros. Tal diferença foi ofuscada pela expressão de "direito subjetivo".

Os direitos fundamentais elaboram o fundamento e o parâmetro da igualdade jurídica, pois atende aos interesses e expectativas de todos, é os conjuntos de garantias asseguradas pelo paradigma do Estado de Direito.

Faz referência à moderna natureza supranacional da grande maioria dos direitos fundamentais.

Refere-se às relações entre direitos e suas garantias. (FERRAJOLI, 2011, p. 15-16)

A quarta tese é a mais importante, pois os Direitos Fundamentais se constituem entre expectativas positivas ou negativas, às quais "correspondem deveres (de prestações) ou proibições (de lesão)". (FERRAJOLI, 2011, p. 16).

Ferrajoli (2011, p. 16) chama de garantias primárias os deveres e as proibições citados anteriormente e de garantias secundárias os deveres de reparar ou sancionar judicialmente as lesões dos direitos, logo, as violações das suas garantias primárias. Infelizmente, não apenas são violadas, como sequer são estabelecidas normativamente.

É importante diferenciar direitos fundamentais e direitos patrimoniais no que se refere à forma e à estrutura de cada um. Enquanto direitos fundamentais são direitos universais, "no sentido lógico da quantificação universal da classe dos sujeitos que deles são titulares", os patrimoniais - de direito de propriedade à direito de crédito - são singulares, pois, para cada, um há um titular determinado (FERRAJOLI, 2011, p. 9).

Existem também os direitos patrimoniais exclusivos, base de desigualdade jurídica, em que Ferrajoli (2011, p. 20) faz a comparação de que todos são igualmente livres para expressar o seu pensamento; todos também são livres de prisões 
arbitrárias e titulares de direito à saúde e à instrução. Porém, cada um é proprietário ou credor de coisas diferentes.

Outra grande diferença é que os direitos fundamentais são direitos indisponíveis, inalienáveis, invioláveis, intransponíveis e personalíssimos, enquanto os patrimoniais são disponíveis, negociáveis e alienáveis, bem como podem se acumular, diferentemente dos primeiros que permanecem invariáveis. Ferrajoli (2011, p. 21) cita uma frase relevante para esclarecer essa diferenciação: "não é possível se tornar juridicamente mais livre, enquanto é possível se tornar juridicamente mais rico".

Logo, pode se observar que os direitos patrimoniais podem ser constituídos, modificados ou extintos por atos jurídicos, ao contrário dos direitos fundamentais, que são ex lege, isto é, conferem-se por meio de regras gerais constitucionais. Segundo Ferrajoli (2011, p. 23), “[...] enquanto direitos fundamentais são normas, os direitos patrimoniais são predispostos por normas."

A última diferença formal é que os direitos patrimoniais são horizontais, e os direitos fundamentais são verticais. Isso porque as relações jurídicas dos titulares dos primeiros são relações intersubjetivas civilísticas (contratual); já os titulares dos segundos são relações publicísticas, ou seja, do indivíduo nos confrontos com o Estado.

Tratando-se especificamente dos direitos fundamentais, pode se destacar que a democracia constitucional consiste nesses direitos, sendo inscritos nas Constituições, operando como fontes de invalidação e deslegitimação. Tanto é que essas normas são dotadas de rigidez absoluta.

Ferrajoli (2011, p. 28) defende que a "[...] democracia constitucional é filha da filosofia contratualista", pois as Constituições são contratos sociais escritos e positivados, formados pela convivência civil ao longo dos tempos. 
O fundamento dos direitos estudados é a dignidade, logo os direitos fundamentais constituem explicitações da dignidade da pessoa humana, sendo que em cada um dos direitos protegidos se encontra algum conteúdo ou alguma projeção desta.

Se os direitos fundamentais foram com o tempo sendo ampliados e conquistados, deve-se salientar com tamanha relevância a grande contribuição de Thomas Hobbes, pois foi com ele que nasceu a configuração do Estado como uma esfera pública formada para garantir a paz e, consequentemente, os direitos fundamentais. Primeiramente, com Hobbes era apenas a tutela do direito à vida, sendo que, aos poucos, foram se formando outros direitos fundamentais: direitos civis e de liberdade, com base no pensamento iluminista e de revoluções liberais, depois os direitos políticos e, por fim, o direito de greve e direitos sociais, como também os novos direitos à paz, ao ambiente e à informação, porém, nem todos estão constitucionalizados (FERRAJOLI, 2011, p. 29).

Após o nascimento da Organização das Nações Unidas (ONU) e as aprovações de cartas e convenções internacionais sobre direitos humanos é que os direitos fundamentais se tornaram supraestatais, sendo direitos de todos, independentemente de sua cidadania, em que pese esta ser pressuposto de direito fundamental. Como garantias e direitos encontram-se na Constituição Federal de 1988, os direitos fundamentais são divididos em direitos individuais, coletivos, sociais e políticos.

Segundo Firmino (2013, p. 24), os "[...] direitos individuais são aqueles que se caracterizam pela autonomia e oponibilidade ao Estado, tendo por base a liberdade". Portanto, impõe ao Estado uma abstenção, não interferindo nessas liberdades. É a representação da reinserção de homens e mulheres na ordem política. 
Os direitos políticos se fundam na "liberdade-participação", ou seja, a possibilidade de o cidadão participar do processo político.

Já os direitos sociais, contidos no art. $6^{\circ}$ da Constituição Federal, visam à melhoria das condições de existência por meio de prestações do Estado, assegurando serviços de educação, saúde, ensino, habitação, entre outros (BRASIL, 2006). Segundo Gonçalves (2013, p. 171), são os que "tornam homens e mulheres juridicamente credores de prestações do Estado".

Há ainda os direitos coletivos, que são aqueles cujo exercício não cabe a cada indivíduo, mas sim a uma pluralidade de sujeitos. São eles: direito de reunião e de associação, direito de entidades associativas de representarem seus filiados, direito de recebimento de informações de cunho coletivo, entre outros.

Como fonte dos direitos fundamentais, há também as necessidades humanas, como explica Firmino (2013, p. 26):

As necessidades humanas [...] vem sendo consideradas como fontes de direitos fundamentais, tendo em vista, principalmente, os direitos daquelas parcelas excluídas em decorrência da prática de um modelo socioeconômico particular, e que, portanto, são atingidas em sua dignidade por um efeito perverso e injusto de condições de vida impostas pelo alijamento do processo de participação social e pela repressão da satisfação das mínimas necessidades.

Logo, essas privações e carências de certa parte da população impulsionam o surgimento de novas necessidades por meio da consciência dos agentes.

Embora não haja menção na Constituição sobre um dever fundamental, é necessário ter em mente que esses deveres estão ligados e conectados aos direitos fundamentais (direito 
de votar, art. 14, $\S 1^{\circ}$, I; de educar os filhos, art. 205; entre outros) (BRASIL, 2006).

Vê-se que os direitos fundamentais, obviamente, estão expressos na Carta Magna, conferindo-lhes um caráter declaratório, diferentemente das garantias, que são "instrumentos da efetivação dos direitos fundamentais e eminentemente assecuratórias." (FIRMINO, 2013, p. 121). Portanto, não se pode confundi-los, já que as garantias não estão expressas na Constituição Federal.

Firmino (2013, p. 121) elenca algumas características dos direitos fundamentais, quais sejam: inalienáveis (indisponíveis): por não poderem ser negociadas, em que pese não possuírem conteúdo patrimonial; imprescritíveis: não sofrem prescrição, podendo ser praticados ou reclamados sem limite de tempo; irrenunciáveis; e invioláveis.

Pinho (2008, p. 69) elenca outras características além dessas, como: historicidade; inalienabilidade; imprescritibilidade; irrenunciabilidade; universalidade; e limitabilidade.

Os direitos fundamentais são indisponíveis, equivalente à sua subtração tanto às decisões da política quanto ao mercado, por isso não são alienáveis pelo sujeito que dele é titular, já que, por exemplo, não se pode vender a liberdade.

A vida, a liberdade pessoal ou o direito de voto são
fundamentais, não tanto porque correspondem a valo-
res ou interesses vitais, mas porque universais e indis-
poníveis. [...] são um limite, não somente aos poderes
públicos, mas também à autonomia de seus titulares:
nem voluntariamente se pode alienar a própria vida ou
a liberdade (FERRAJOLI, 2011, p. 22).

Quanto à irrenunciabilidade e à inviolabilidade, esta última é pelo fato de os direitos fundamentais não poderem ser desrespeitados por qualquer autoridade e, principalmente, por lei infraconstitucional, sujeito a ilícito civil, penal ou administrativo. 
São universais, pois são impostos a todos, respeitando o princípio da isonomia. Quanto à historicidade de que trata Pinho (2008), significa dizer que são oriundos da evolução histórica, pois surgiram das contradições que existiram e existem em uma sociedade.

Podem se aplicar os princípios da proporcionalidade e da razoabilidade para que se possa exercer vários direitos fundamentais ao mesmo tempo e em um mesmo caso concreto, independentemente se um se contraponha ao outro.

É necessário que haja uma interdependência entre normas constitucionais e infraconstitucionais com os direitos fundamentais, entretanto as primeiras devem zelar pelos objetivos da segunda (FOERSTER, 2007). São complementares por haver a interpretação concomitante dos direitos fundamentais, havendo, assim, uma realização absoluta.

A fiscalização no cumprimento dos direitos fundamentais, em primeiro aspecto, ocorre com a declaração de uma lei inconstitucional pelo Poder Judiciário, quando o conteúdo dessa lei ferir a essência dos direitos fundamentais, bem como com a anulação de atos administrativos pelo mesmo fundamento.

Com isso, tem-se que o Poder Judiciário se vincula aos direitos fundamentais quanto à fiscalização destes, bem como no conteúdo das suas decisões e de seus atos para a condução do processo, devendo respeitar sempre os princípios do contraditório, da ampla defesa, do juiz natural, da proibição de provas ilícitas e da publicidade.

\section{DIREITOS FUNDAMENTAIS SOCIAIS}

Os Direitos Fundamentais Sociais têm uma demasiada relevância jurídica, pois sua essencialidade é tutelada pela Carta Magna, sendo que estão contidos no mínimo existencial, 
englobado no conteúdo jurídico do princípio da Dignidade da Pessoa Humana.

A Constituição Federal de 1988 define quais são os direitos sociais em seu art. $6^{\circ}$ :

Art. $6^{\circ}$ São direitos sociais a educação, a saúde, a alimentação, o trabalho, a moradia, o transporte, o lazer, a segurança, a previdência social, a proteção à maternidade e à infância, a assistência aos desamparados, na forma desta Constituição. (BRASIL, 2016).

Ingo Sarlet (2011, p. 111) define o objetivo principal dos direitos fundamentais sociais em garantir uma existência digna por meio de um mínimo existencial, nos seguintes termos:

Os direitos sociais de cunho prestacional encontram-se a serviço da igualdade e da liberdade material, objetivando a proteção da pessoa contra as necessidades de ordem material e à garantia de uma existência com dignidade, constatação esta que tem servido para fundamentar um direito fundamental [...] a um mínimo existencial, compreendido aqui [...] não como um conjunto de prestações suficientes apenas para assegurar a existência [...] humana, mas uma vida com dignidade no sentido de uma vida saudável como deflui do conceito de dignidade adotado nesta obra [...].

Segundo Pinho (2008, p. 167), eles têm conteúdo econômico-social, com o intuito de melhorar as condições de vida e trabalho para todos, por intermédio de prestações positivas do Estado em prol dos menos favorecidos e setores economicamente mais frágeis.

Eles são intangíveis e irredutíveis, assim qualquer ato que tenda a restringir ou aboli-los torna-se inconstitucional, surgindo, então, o princípio da Proibição do Retrocesso Social, definido por Canotilho (1998, p. 321) como: 
O núcleo essencial dos direitos sociais já realizado e efetivado através de medidas legislativas deve considerar-se constitucionalmente garantido, sendo inconstitucionais quaisquer medidas estaduais que, sem a criação de outros esquemas alternativos ou compensatórios, se traduzam na prática numa "anulação", "revogação" ou "aniquilação" pura e simples desse núcleo essencial. A liberdade do legislador tem como limite o núcleo essencial já realizado.

Logo, mesmo que não explícito no ordenamento jurídico, o princípio da Proibição do Retrocesso Social tem aplicabilidade plena, assim como o direito de resistência e o princípio da dignidade da pessoa humana, por isso ele se torna corolário do que o ser humano deve dar valor, que é a sua dignidade.

Segundo Firmino (2013, p. 277), o Estado perde o controle de sua economia, e isso, dependendo da ocasião, favorece ou desfavorece a aplicabilidade dos direitos sociais. Por isso é que se deve proteger, ao menos, o necessário a uma vida digna:

Em um país tão marcado pela desigualdade social como o Brasil, os impactos do processo de globalização econômica e os matizes neoliberais políticos fazem por brotar no constitucionalismo contemporâneo a necessidade de elaborar formas de proteger os direitos sociais, em especial os trabalhistas, garantindo o mínimo necessário à dignidade de vida. Tido como direitos prestacionais, não são meros poderes de agir, porém, são poderes de exigir, pois são direitos subjetivos.

Quanto à leitura desses direitos em Carta Magna, Firmino (2013, p. 272) destaca que não se pode fazer uma leitura restritiva dos direitos sociais como normas programáticas:

A leitura restritiva dos direitos fundamentais resulta em notável prejuízo ao cidadão, porque esta terá seu patrimônio jurídico reduzido. Isto ocorre de forma numérica, 
quando reduz o rol de direitos fundamentais de forma sofisticada, através do enquadramento dos direitos sociais como normas programáticas.

Ademais, a análise crítica dos direitos fundamentais sociais no conceito frágil de normas programáticas não faz sentido, uma vez que os valores sociais são os pilares do Estado Democrático de Direito.

Os direitos fundamentais sociais são os que mais fomentam um debate sobre sua exigibilidade judicial, isto é, sua dimensão prestacional é mais evidente, tendo, portanto, uma relevante dimensão econômica, já que cobram uma destinação de recursos para serem satisfeitos. Por isso, são chamados de normas programáticas, pois não são concretizados desde logo, dependendo, desse modo, de intervenção legislativa e administrativa para isso.

\section{EFICÁCIA SOCIAL DOS DIREITOS FUNDAMENTAIS SOCIAIS}

Ao falar de eficácia, está se referindo sobre a capacidade de os objetivos serem atingidos quando fixados previamente como metas. Ou seja, no mundo jurídico, é a capacidade de realizar os ditames jurídicos que foram observados pelo legislador. Porém, uma norma pode ter a sua eficácia jurídica, mas não a eficácia social, já que, no plano social, ela pode não estar sendo cumprida. É o que ocorre, muitas vezes, com os direitos fundamentais sociais.

Sabe-se que, para que haja uma melhor eficácia de normas que asseguram direitos, como: saúde, educação, assistência social, moradia, trabalho, é necessário que haja certos questionamentos, como as condições econômico-financeira do Estado e a competência do Judiciário para intervir nas políticas públicas, sendo, por meio destas, o alcance dos efeitos 
dos direitos sociais, pois, para a eficácia dos direitos, sempre há um custo. Logo, é preciso haver um conjunto de ações no tocante à aplicação de normas sociais ao delinear as necessidades básicas sociais, ao defini-las, ao estabelecimento de políticas públicas relevantes, priorizando o planejamento orçamentários destas, entre outras ações.

Assim, há a necessidade de se analisar cuidadosamente o significado do art. $5, \S 1^{\circ}$, da Constituição, que dispõe o seguinte: "Art. $5 . \S 1^{\circ}$ - as normas definidoras dos direitos e garantias fundamentais têm aplicação imediata". (BRASIL, 2016)

Mesmo que o referido artigo esteja inserido no capítulo dos direitos individuais e coletivos, a doutrina reconhece que a aplicação desse dispositivo não é restrita, mas sim conferida a todas as normas que definem os direitos fundamentais previstos na Constituição.

Portanto, ao se considerar os direitos sociais como fundamentais, leva-se em consideração também que, segundo o que estabelece a Constituição, eles têm aplicação imediata. Entretanto, infelizmente, não é essa realidade prática que se visualiza na sociedade.

Muitos direitos fundamentais sociais não são aplicados imediatamente, e muitos até são violados. Vê-se isso quando se analisa a justiciabilidade deles, quanto ao fato de o cidadão ter que recorrer à justiça para ter a tutela desse direito.

Os direitos fundamentais sociais têm a necessidade de uma integração maior de eficácia a ser concretizada no plano infraconstitucional. Quanto a isso, assim explica Cláudia Gonçalves (2013, p. 176):

No que concerne aos direitos sociais, formalizados enquanto normas programáticas, isso assegura certos limites à ação política da maioria, a fim de que o exercício dos poderes constituídos não rasure a opção jusfunda- 
mental expressa na Carta de 1988, para a qual, inclusive, contribuíram amplos segmentos populares.

Segunda a mesma autora, a Constituição define quais os conteúdos devem necessariamente compor os direitos fundamentais sociais, quais sejam: saúde preventiva e curativa (arts. $6^{\circ}$ e 196); educação básica obrigatória dos 4 anos aos 17 e especializada aos portadores de deficiência, garantida a sua gratuidade, além de creches e pré-escolas (art. 208, I, III e IV); atendimento ao educando, como material, transporte, alimentação e assistência à saúde (art. 208, VII); trabalho com remuneração que atenda à dignidade humana e ao ambiente seguro (art. $7^{\circ}$, IV, VII e XXII); direito ao descanso do trabalhador (art. $7^{\circ}$, XIII, XIV, XV, XVI e XVII); moradia segura e com condições básica de higiene e saúde (art. $6^{\circ}$ c/c $1^{\circ}$, III); previdência social (art. $6^{\circ}$ ); assistência social (art. $6^{\circ}$ e 203 ); alimentação adequada (art. $6^{\circ}$ ); e assistência jurídica gratuita (art. $5^{\circ}$, LXXIV). Esses conteúdos que devem compor os direitos sociais ultrapassam o conteúdo mínimo, porém não as necessidades humanas básicas (BRASIL, 2016).

Tendo em vista que a eficácia dos direitos fundamentais sociais está pautada na aplicabilidade de políticas públicas, estas se regem por princípios constitucionais, que são: Estado Democrático de Direito; Dignidade Humana; Universalidade, Igualdade e Seletividade; Descentralização e Participação Popular; Reserva do Possível; Proibição do Retrocesso; Segurança Jurídica; Uniformidade e Diferenciação Regional; Proporcionalidade ou Proibição de Excessos (GONÇALVES, 2013, p. 190).

Verifica-se que, dentre esses, estão incluídos também princípios essenciais ao se tratar da eficácia dos Direitos Fundamentais Sociais, que são a Dignidade Humana, a Reserva do Possível e a Proibição do Retrocesso.

Para Ana Lúcia Pretto Pereira (2014, p. 101), os direitos fundamentais, principalmente os sociais, possuem duas dimen- 
sões para a sua efetividade: uma objetiva, que impõe um dever de observância e respeitabilidade quanto aos princípios que abrigam; e a outra subjetiva, que admite a sua exigibilidade judicial em alguma medida.

A justiciabilidade, ou seja, a exigibilidade judicial, diz respeito à possibilidade de os bens jurídicos abrigados pelos direitos fundamentais sociais serem exigidos ao judiciário de forma direta. Assim, esses direitos "consubstanciam a proteção de elementos básicos ao progresso individual e coletivo dos cidadãos" (PEREIRA, 2014, p. 103) (saúde, educação, trabalho, moradia, lazer, segurança, previdência social, proteção à maternidade e à infância e a assistência aos desamparados e à alimentação), ou seja, os que satisfazem as necessidades humanas fundamentais.

Assim, conclui-se que a eficácia social plena dos direitos fundamentais sociais depende muito da atuação do Estado para com políticas públicas e distribuição de recursais nas esferas sociais da sociedade para que o cidadão consiga uma vida digna, com um conteúdo mínimo de direito.

\section{CONTEÚDO MÍNIMO DOS DIREITOS FUNDAMENTAIS SOCIAIS}

O conteúdo mínimo de direitos fundamentais sociais que todos têm direito depende da destinação de recursos públicos, significando um mínimo exigível de aplicação, e este está relacionado ao Princípio da Dignidade da Pessoa Humana, já que é o mínimo de direito que a pessoa precisa para ter uma vida humana digna.

A ideia de que os direitos prestacionais não são absolutos, somente podendo ser cumpridos dentro dos limites do orçamento público, caracteriza o Princípio da Reserva do Possível, exigindo uma atuação positiva do Estado com uma previsão no seu orçamento para serem caracterizados. Portanto, a concre- 
tização dos direitos sociais é progressiva, ou seja, não é integral, ocasionando, muitas vezes, a frustração do direito em sua efetividade. Assim, caso o direito social à saúde, por exemplo, não possuir lastro financeiro previsto, acarretará a sua não concretização, como acontece, realmente, em alguns casos.

Desse modo, há quem defenda que o Poder Judiciário não pode obrigar o Estado a prestar algum direito se essa prestação ocorra aquém do que o orçamento prevê. Em relação a isso, assim afirma Firmino (2013, p. 255): "O princípio da reserva do possível não pode ser uma espécie de "carta branca" para o Estado deixar de cumprir a sua obrigação, sob a afirmação de que não há recursos disponíveis".

Entretanto, se um direito se depara na reserva do possível do seu mínimo, ainda assim deve estar garantido para que seja condizente com a dignidade da pessoa humana. Porém, qual será esse "mínimo"? Para descobrir isso, há de se adentrar no Princípio do Mínimo Existencial, que se contrapõe com o princípio anteriormente estudado.

O mínimo existencial nada mais é que a junção de situações materiais (necessidades) que são consideradas indispensáveis para a existência humana digna, sendo considerada, além de corpórea, também existência espiritual e intelectual.

Para Ana Lúcia Pereira (2014, p. 107), a doutrina ainda não conseguiu conceituar mínimo existencial, já que este é uma junção de valores que estão ligados às necessidades sociais que variam de acordo com o contexto histórico.

Firmino (2013, p. 256) explica que, "diante das disparidades socioeconômicas entre as pessoas, o mínimo existencial pressupõe que se faça um raciocínio equitativo, que conduziria ao resultado mais justo ou menos injusto", de forma a garantir que cada um receba um conjunto mínimo de condições materiais para a sua existência. 
Para a eficácia do princípio da dignidade da pessoa humana, é necessário que o mínimo social existencial seja ofertado pelo Estado, já que esse princípio não se encontra sem um mínimo de direitos sociais necessários para a sua sobrevivência.

O Estado deve oferecer condições para que o cidadão consiga desenvolver a sua própria dignidade de forma autônoma, mesmo com a necessidade de despesas para a garantia do mínimo existencial, já que é um direito de todos. Quanto a isso, assim explica Ana Lúcia Pereira (2014, p.107-108):

A necessidade fundamental de que se cuida, aqui, é aquela proposta pela teoria das necessidades, e que seria imprescindível ao desenvolvimento da autonomia humana. Sem o atendimento dessas necessidades, não há autonomia pública e privada, não há cidadania, não há vida digna, não há dignidade humana. Nesse patamar, defende-se que não há argumento de escassez de recursos que impeça o acesso do sujeito aos satisfadores de tais bens fundamentais.

De acordo com Firmino (2013, p. 256), é relevante se ter um conteúdo básico de prestações dos direitos sociais, quais sejam: saúde básica digna, acesso à justiça e assistência aos desamparados, que engloba alimentação, vestuário, abrigo e educação fundamental. Até porque, ao se deparar com a dúvida do que seria o mínimo existencial, deve-se relacioná-lo aos artigos da Constituição que tratam da educação, da saúde, do salário mínimo, pois o artigo sobre direitos fundamentais somente menciona quais são eles, não menciona como seriam, se devem ser analisados os artigos referentes a cada um.

Há de haver um equilíbrio entre o emprego da reserva do possível e do mínimo existencial para impedir retrocessos nas conquistas sociais, chegando, de acordo com Firmino (2013, p. 258), a uma solução "à luz da dignidade da pessoa humana", 
qual seja, a da garantia das condições mínimas pelo Estado, desenvolvendo e assegurando a dignidade das pessoas. Assim, de acordo com Ana Lúcia Pereira (2014, p. 129), o Estado não pode utilizar o argumento da Reserva do Possível por razões financeiras, já que não podem se sobrepor à "necessidade de proteção do bem maior da dignidade humana, que é a vida".

Fala-se do afastamento da reserva do possível pelo fato de os direitos fundamentais sociais poderem ser demandados em juízo, ou seja, é a tese da justiciabilidade, que nada mais é do que a possibilidade desses direitos serem litigados no Judiciário.

Isso ocorre quando há uma deficiência de políticas públicas, que levam à frustração dos direitos fundamentais sociais, prejudicando a sua efetividade, assim, aqueles que se sentem lesados demandando judicialmente pela concretização dos direitos pelo Estado. Porém, o que se demanda é a satisfação das necessidades humanas fundamentais, e não o mínimo (PEREIRA, 2014, p.185).

Há julgados que afastam o argumento da reserva do possível e, ao fazerem isso, se aproximarão do princípio do Devido Processo Legal Substantivo, pois ele se configura elemento que legitima o controle judicial sobre os atos legislativos e administrativos. Não obstante também o fato de que o mínimo existencial deve ser atendido em primeiro lugar para que, então, se possa discutir quanto à aplicação dos recursos públicos remanescentes que se referem à Reserva do Possível.

Cláudia Gonçalves (2013, p. 178) comenta acerca do pensamento de Rawls, autor que defende que a garantia do mínimo social é um pressuposto para o exercício da liberdade.

Urge salientar que conteúdo mínimo é diferente de necessidades básicas, pois o primeiro é geral, ou seja, todos precisam de um pouco de cada direito para se ter uma vida digna. Enquanto necessidades básicas, conforme Doyal e Gough, são o 
básico para a vida do cidadão, não necessitando englobar todos os direitos. Segundo esses autores, a saúde física e a autonomia são necessidades básicas objetivas e universais (GONÇALVES, 2013, p. 179).

Os direitos fundamentais sociais têm certa autonomia, no sentido de reconhecê-la como instrumento de diálogo e de luta política entre seres humanos portadores de deveres e direitos perante o Estado e a sociedade civil. Essa autonomia significa dizer que todos tenham, a médio e longo prazo, direito ao básico de direitos, e não apenas direito ao mínimo, segundo afirma Cláudia Gonçalves (2013, p. 189).

Logo, o conteúdo mínimo existencial deve ser atendido sempre em primeiro lugar, respeitando, portanto, a dignidade da pessoa humana para que haja uma existência digna do ser humano.

\section{DIGNIDADE DA PESSOA HUMANA GARANTIDA POR MEIO DOS DIREITOS FUNDAMENTAIS SOCIAIS}

O Princípio da Dignidade da Pessoa Humana está assegurado e positivado no art. $1^{\circ}$ da Constituição vigente, declarando-o como um dos fundamentos da República Federativa do Brasil. Essa dignidade é o valor que todo homem possui intrinsecamente, como de pronto afirmou Ingo Sarlet (2011, p. 50).

Com isso, o autor também remete ao problema de se encontrar um significado para a dignidade humana, além da ideia de um valor intrínseco à pessoa humana.

O valor dignidade que está intrínseco a todo homem advém de Kant, ao enunciar a segunda fórmula do imperativo categórico de que "age de forma que trates a humanidade, tanto na tua pessoa como na pessoa de qualquer outros, sempre também como fim e nunca unicamente como meio" (FIRMINO, 2013, p. 348). 
Já fora abordado que, nos direitos fundamentais, há explicitações da dignidade da pessoa humana e que em cada um daquele há algum conteúdo desta. Todavia, não são todos os direitos fundamentais que encontram seu fundamento direto nesse princípio, tendo em vista que a eficácia e a inviolabilidade da dignidade da pessoa humana encontram relação e até uma dependência da capacidade de se integrar aos direitos fundamentais.

Portanto, a dignidade da pessoa humana, na condição de valor, exige o reconhecimento e a proteção dos direitos fundamentais, pois as pessoas são titulares de direitos humanos em virtude de sua dignidade, e os seus direitos têm por objetivo conferir-lhes uma existência digna.

Ingo Sarlet (2011, p. 102) defende a premissa de que os direitos fundamentais constituem explicitações da dignidade da pessoa, fazendo presente em cada um daquele um conteúdo ou alguma projeção desta.

A questão sobre essa relação entre direito fundamental e dignidade da pessoa humana consiste no fato pelo qual as pessoas são titulares de direito humanos em função da sua dignidade inerente.

Os direitos fundamentais, assim como também o direito de igualdade, estão diretamente ancorados na dignidade da pessoa humana, em que pese a Declaração Universal da ONU consagrar que todos os seres humanos são iguais em dignidade e direitos.

Portanto, com base nisso, é que o pressuposto essencial para o respeito da dignidade da pessoa humana é a garantia da isonomia de todos os seres humanos. As necessidades humanas básicas agregam por igual as liberdades e os direitos fundamentais sociais, englobando objetivamente a dignidade humana.

Logo, vê-se que quem garante a Dignidade da Pessoa Humana do art. $1^{\circ}$ da Constituição são os direitos do art. $6^{\circ}$ do mesmo dispositivo (BRASIL, 2016). Ou seja, os direitos fun- 
damentais sociais (saúde, educação, entre outros) são os que garantem o princípio ora estudado.

Portanto, conforme o que fora aqui estudado, a Dignidade da Pessoa Humana não existirá sem se ter um conteúdo mínimo necessário de direitos fundamentais sociais para a sua existência, já que esses direitos, pode-se dizer, são pressupostos para que a dignidade possa existir.

\section{CONCLUSÃO}

Ao concluir a presente pesquisa, vê-se que o valor da pessoa, ou seja, a sua dignidade encontra a sua expressão jurídica nos direitos fundamentais sociais. Viu-se que a eficácia dos direitos ora estudados são de extrema relevância para a garantia do Princípio da Dignidade da Pessoa Humana ou, ao menos, um Conteúdo Mínimo daquele.

Os direitos fundamentais sociais são os que mais demandam uma destinação de recursos do Estado, tendo em vista que o objetivo principal deles é aprimorar a vida e o trabalho do cidadão para cumprir com um dos fundamentos da República brasileira, que é a dignidade da pessoa humana. Com isso, verifica-se que muitos não possuem aplicabilidade imediata e, por isso, não apresentam uma eficácia plena.

Necessitando de uma ação positiva do Estado para a sua eficácia, eles são tidos como direitos prestacionais, já que, em sendo subjetivos, o cidadão titular deste tem o poder de exigir do Estado a sua devida prestação.

Viu-se que, ao ter um conflito entre o Conteúdo Mínimo ou a Reserva do Possível, deve-se levar em consideração o primeiro, pois é necessário para que haja uma efetivação da dignidade humana e eficácia dos direitos sociais, já que estes, definidos pela Constituição de 1988, são, portanto, fundamentais à existência digna de todo cidadão. 
Porém, verificou-se que o problema está justamente nessa eficácia dos direitos, pois ela depende de políticas públicas do Estado, já que é dever deste e direito de todos os cidadãos. O problema é que, ao colocar em prática essas políticas públicas, o Estado não realiza de modo eficaz os direitos sociais, já que alega a Reserva do Possível, ou seja, faz alegações que o orçamento do Estado não é suficiente para atender a toda a demanda da população, portanto um ou outro direito não irá ter a sua eficácia plena e imediata.

Com isso, o cidadão usa a justiciabilidade, ou seja, procura na justiça a tutela do seu direito. Muitos propõem ações para conseguirem vagas em creches, remédios, tratamentos cirúrgicos, enfim, procuram o Judiciário para obrigar o Estado a efetivar determinado direito para o caso concreto. Assim, verificou-se que muitas vezes o Juiz afasta a alegação do Estado quanto à Reserva do Possível e aplica o Conteúdo Mínimo Existencial, pois a decisão do juiz, além de respeitar os direitos fundamentais, também deve respeitar os princípios da dignidade da pessoa humana, e estes não serão respeitados caso seja deferida a alegação da Reserva do Possível.

O fato de o legislador estabelecer vedações para o poder reformador e proteger os seus direitos evita o esvaziamento do conteúdo constitucional, tendo, então, uma constituição rígida, levando como base o Princípio da Proibição do Retrocesso Social. Não havendo, portanto, uma aplicação efetiva dos direitos sociais, ao menos no seu mínimo existencial, não há o que se falar em dignidade da pessoa humana, pois, como visto, esse princípio somente é garantido se houver um conteúdo mínimo de direitos fundamentais sociais de forma efetiva, por meio de políticas públicas.

Assim, sendo a pessoa um sujeito de direitos e obrigações e a dignidade da pessoa humana, um fundamento da Consti- 
tuição, é um direito dela (de todo os cidadãos) ser titular, portanto, de direitos fundamentais que assegurem e promovam de forma efetiva a sua condição como pessoa, com dignidade.

Depreendeu-se, então, que a eficácia dos direitos fundamentais sociais, positivado na Carta Magna, ainda deve superar muitos obstáculos, porém se faz necessário, frente ao direito a uma vida digna, fundamento da Constituição de 1988.

\section{REFERÊNCIAS}

BRASIL. [Constituição (1988)]. Constituição da República Federativa do Brasil de 1988. Brasília, DF: Presidência da República, 2006. Disponível em: http://www.planalto.gov.br/ccivil_03/Constituicao/ Constituiçao.htm. Acesso em: 09 fev. 2020.

CANOTILHO, Joaquim José Gomes. Constitucional e teoria da Constituição. 3. ed. Coimbra: Almedina, 1998.

FERRAJOLI, Luigi. Por uma teoria dos direitos e dos bens fundamentais. Porto Alegre: Livraria do Advogado, 2011.

FIRMINO, Nelson Flávio. Curso de direitos fundamentais. Curitiba: Juruá, 2013.

FOERSTER, Gabriele. Direitos e garantias fundamentais na Constituição Federal de 1988. Viajus, 2007. Disponível em http://www.viajus. com.br/viajus.php?pagina $=$ artigos\&id=1052\&idAreaSel $=16 \&$ seeAr$\mathrm{t}=\mathrm{yes}$. Acesso em: 9 fev. 2020.

GONÇALVES, Cláudia Maria da Costa. Direitos fundamentais sociais: uma releitura de uma Constituição dirigente. Curitiba: Juruá, 2013.

MACHADO, Diego Pereira. Direitos humanos. 3. ed. Salvador: Jus Podivm, 2015.

PEREIRA, Ana Lúcia Pretto. Reserva do possível: judicialização de políticas públicas e jurisdição constitucional. Curitiba: Juruá, 2014.

PINHO, Rodrigo César Rebello. Teoria geral da Constituição e direitos fundamentais. 8. ed. São Paulo: Saraiva, 2008. 
SARLET, Ingo Wolfgan. Dignidade da pessoa humana e direitos fundamentais na Constituição Federal de 1988. 9. ed. Porto Alegre: Livraria do Advogado, 2011.

SARLET, Ingo Wolfgang. A eficácia dos direitos fundamentais. 6 . ed. Porto Alegre: Livraria do Advogado, 2006.

Recebido em: 16/04/2020

Aprovado em: 20/07/2020 